\title{
Quantitative detection of HER2 protein concentration in breast cancer tissue does not increase the number of patients eligible for adjuvant HER2-targeted therapy
}

\author{
TROELS BECHMANN ${ }^{1,2}$, DORTE AALUND OLSEN ${ }^{3}$, ERIK HUGGER JAKOBSEN $^{2}$, \\ JONNA SKOV MADSEN ${ }^{1,3}$, IVAN BRANDSLUND ${ }^{1,3}$, ANNE MARIE BAK JYLLING ${ }^{4}$, \\ KARINA DAHL STEFFENSEN $^{1,5}$ and ANDERS JAKOBSEN ${ }^{1,2}$
}

\begin{abstract}
${ }^{1}$ The Faculty of Health Sciences, University of Southern Denmark, Odense; Departments of ${ }^{2}$ Oncology and ${ }^{3}$ Biochemistry, Vejle Hospital, Vejle; Departments of ${ }^{4}$ Pathology and ${ }^{5}$ Oncology, Odense University Hospital, Odense, Denmark
\end{abstract}

Received November 23, 2012; Accepted January 4, 2013

DOI: 10.3892/or.2013.2289

\begin{abstract}
Human epidermal growth factor receptor-2 (HER2) is overexpressed in 15-20\% of breast cancer patients and is associated with an aggressive tumor and a poor prognosis. Currently, patients are selected for adjuvant HER2-targeted therapy based on HER2 status by immunohistochemistry (IHC) and fluorescence in situ hybridization (FISH). In this study, we assessed the clinical significance of tissue HER2 status determined by a quantitative immunoassay using ADVIA Centaur. We investigated the hypothesis that the clinical outcome is worse in a group of patients defined as tissue HER2-positive only by Centaur, but not treated with adjuvant HER2-targeted therapy, compared to patients defined as HER2-positive by IHC/FISH and therefore treated with adjuvant HER2-targeted therapy. Tumor tissue was obtained at primary surgery from 415 breast cancer patients between 2004 and 2010. HER 2 status was determined by quantitative immunoassay of fresh-frozen tissue and by IHC/FISH of corresponding paraffin-embedded tissue. We compared the clinical outcome in four groups of patients defined by tissue HER2 status and adjuvant HER2-targeted therapy. The final analysis included 379 patients after a median followup of 3.9 years for invasive disease-free survival (IDFS) and 4.2 years for overall survival (OS). The quantitative Centaur assay defined a greater number of patients (100 patients, $26.4 \%)$ as HER2-positive than IHC/FISH (63 patients, 16.6\%) $(\mathrm{P}<0.0001)$. No significant difference in IDFS $(\mathrm{P}=0.159)$ and $\mathrm{OS}(\mathrm{P}=0.150)$ was observed among the four groups of patients. However, in the IHC/FISH-positive group without adjuvant HER2-targeted therapy (group 2), a significantly greater number of events was found compared to the Centaur-positive group without adjuvant
\end{abstract}

Correspondence to: Dr Troels Bechmann, Department of Oncology, Vejle Hospital, Kabbeltoft 25, DK-7100 Vejle, Denmark

E-mail: troels.bechmann@slb.regionsyddanmark.dk

Key words: breast cancer, human epidermal growth factor receptor-2, ADVIA Centaur, quantitative human epidermal growth factor receptor-2
HER2-targeted therapy (group 3$)$ for both IDFS $(\mathrm{P}=0.025)$ and OS ( $\mathrm{P}=0.020)$. Quantitative HER 2 determination by Centaur did not define a new group of patients eligible for HER2-targeted therapy. Currently, tissue HER2 status defined by IHC/FISH analysis remains the gold standard.

\section{Introduction}

Breast cancer is the leading cancer among women in the industrialized world and $15-20 \%$ of breast cancer tumors feature an overexpression and/or amplification of human epidermal growth factor receptor-2 (HER2). HER2, also termed HER2/neu, ErbB2 or p185HER2, is one of four tyrosine kinase receptors of the HER family which includes HER1 (EGFR), HER2, HER3 and HER4. The HER2 gene is located on chromosome 17 and encodes HER2, which is a 185-kDa glycoprotein composed of an intracellular tyrosine kinase domain, a transmembrane domain, and an extracellular domain with a yet unknown ligand (1). Activation of the HER2 pathway is presumably driven by the binding of heregulins to HER3 and HER4 or EGF to HER1 and the subsequent hetero-dimerization with HER2, which leads to the activation of the downstream pathway (2).

Overexpression of the HER2 protein and/or amplification of the HER2 gene leads to tumor cell proliferation and is associated with an aggressive tumor and a poor prognosis $(3,4)$. Furthermore, HER2 overexpression/amplification predicts the effect of HER2-targeted therapy (e.g., trastuzumab and lapatinib) in combination with chemotherapy in both the metastatic and adjuvant setting, and several studies have demonstrated that the addition of trastuzumab reduces the risk of recurrence in HER2positive breast cancer patients by approximately 50\% (5-7).

Several studies have reported the discordance of HER2 status between primary and recurrent disease years after the primary treatment in $3-14 \%$ of the cases (8-10). This has led to the hypothesis that an additional group of patients may benefit from HER2-targeted therapy in the adjuvant setting. However, it remains unclear whether the observed discordance of HER2 status is due to heterogeneity of the primary tumor, acquired HER 2 expression during the course of the disease, or limited sensitivity of the assay leading to misclassification of a modest, 
but clinically relevant HER 2 overexpression. Currently, patients are selected for adjuvant HER2-targeted therapy based on immunohistochemistry (IHC) and fluorescence- or chromogenic in situ hybridization (FISH, CISH) (11). In addition to these semi-quantitative tests, quantitative real-time PCR and microarray-based RNA expression analysis of HER2 have emerged over the past decade, delivering quantitative estimates of HER2 DNA and RNA expression (12-14).

In this study, tissue HER 2 status was determined by a quantitative immunoassay using ADVIA Centaur. This assay is able to analyze a larger tumor amount, whereby the influence of tumor heterogeneity is reduced compared to IHC/FISH. By using this method, an additional $9 \%$ of patients were classified as HER2-positive compared to the conventional IHC/FISH methods as reported in a previous study by Olsen et al (15). The clinical relevance of this information however, is unknown and therefore, the aim of the present study was to perform a clinical evaluation of the quantitative Centaur assay. We wished to examine the hypothesis that the clinical outcome is poorer in a group of patients defined as tissue HER2-positive by Centaur only, but not treated with adjuvant HER2-targeted therapy, compared to patients defined as HER2-positive by IHC/FISH and therefore treated with adjuvant HER2-targeted therapy.

\section{Patients and methods}

Study population and patient samples. This prospective cohort study was performed in a single center cancer hospital. Women eligible for primary surgery for breast cancer stages I-IIIA were included after written informed consent. The study was approved by the Regional Scientific Ethics Committee for Southern Denmark (project identification number S-VF20040101). Tumor tissue samples and autologous reference tissue samples were obtained from 415 breast cancer patients between 2004 and 2010. Surgery was performed in accordance with the guidelines from the Danish Breast Cancer Cooperative Group (DBCG).

The tissue samples were obtained within $1 \mathrm{~h}$ after surgery. One part of the sample was fixed in formalin and paraffinembedded for IHC/FISH analysis. The other part of the sample was snap-frozen in liquid nitrogen and stored in a local biobank at $-80^{\circ} \mathrm{C}$ for later Centaur analysis. A dedicated pathologist verified the presence of tumor tissue in the tumor sample and the lack of tumor tissue in the autologous reference tissue. Reference tissue was taken at least $1 \mathrm{~cm}$ away from tumor tissue whenever possible.

A total of 36 patients were excluded from the final analysis due to advanced disease, benign pathology, neoadjuvant chemotherapy, or missing tumor tissue (flow diagram, Fig. 1). The mean age of the remaining 379 patients was 60 years (34-91 years). A total of 272 patients (71.8\%) were treated with breast-conserving surgery, while $107(28.2 \%)$ had a mastectomy. Only 17 patients (4.5\%) had bilateral synchronous breast cancer. The majority of patients (330 patients, $87.1 \%$ ) had invasive ductal carcinoma, 25 patients (6.6\%) had invasive lobular carcinoma, and 24 patients (6.3\%) had other types of breast cancer.

End points. End points were defined according to the standard definitions by Hudis et al (16) Invasive disease-free survival

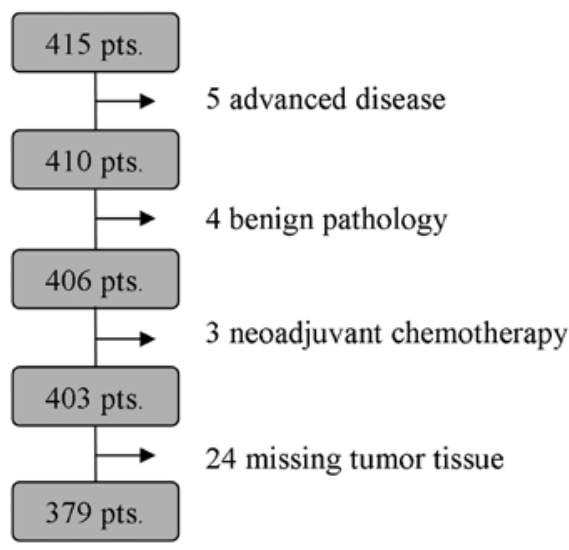

Figure 1. Diagram outlining the exclusion of patients. pts, patients.

(IDFS) was defined as the time from primary surgery to one of the following events: ipsilateral invasive breast tumor recurrence, regional invasive breast cancer recurrence, distant recurrence, death by any cause, contralateral invasive breast cancer, or second primary non-breast invasive cancer. This definition excludes all types of carcinoma in situ [ductal carcinoma in situ (DCIS), lobular carcinoma in situ (LCIS) and all in situ cancers of non-breast sites] and squamous or basal cell skin cancers. Overall survival (OS) was defined as the time from primary surgery to death by any cause (includes death from breast cancer, non-breast cancer or unknown causes).

Clinical and histological data. Pathological data were obtained from the DBCG database and verified in the local database at the Department of Pathology, Vejle Hospital, Vejle, Denmark. Clinical IDFS data were obtained from the local electronic health records and the nationwide online electronic health records holding data from all Danish hospitals. OS data were obtained from the nationwide Danish Civil Registration System, which contains basic personal data on all residents in Denmark.

Tissue HER2 determination. Homogenization of the tissue samples and determination of the tissue HER2 status and estrogen receptor (ER) status have been described in detail in a previous study of ours [Olsen et al (17)]. The quantitative detection of HER2 tissue concentration was determined using fresh-frozen tumor tissue and autologous reference tissue by means of commercially available HER2/neu assay using the ADVIA Centaur system (Siemens Healthcare Diagnostics, Deerfield, IL, USA). This automated immunoassay uses two monoclonal antibodies (TA-1 and NB-3) for the detection of HER2 protein. The chemiluminescence signal is directly proportional to the quantity of HER2 protein in the sample. Each assay was controlled by two commercial controls (Siemens Healthcare Diagnostics) and one in-house serum pool. The assay shows an acceptable inter-assay coefficient of variation (CV) between 4.4 and $5.6 \%$.

Tissue HER2 status was determined on paraffinembedded tumor tissue using the IHC and FISH methods. The tumors were considered HER2-positive if defined $\mathrm{IHC}^{+}$or $\mathrm{IHC}^{+}$combined with FISH $\geq 2$. IHC analysis was assessed by HercepTest ${ }^{\mathrm{TM}}$ (DakoCytomation, Glostrup, Denmark). 


\section{HER2 status by IHC/FISH and Centaur}

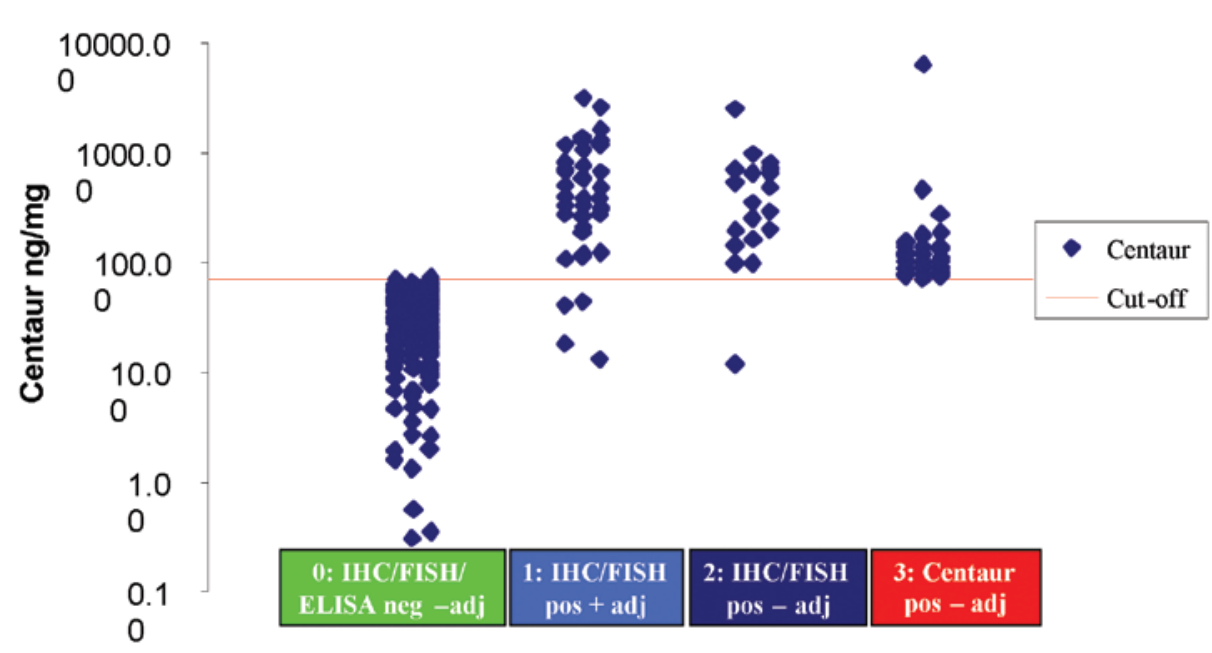

Figure 2. Distribution of ADVIA Centaur values according to the four different groups of patients defined by tissue HER 2 status (IHC3 ${ }^{+}$or IHC2 $2^{+}$with FISH $\geq 2$ or Centaur $>72 \mathrm{ng} / \mathrm{mg}$ cut-off value), +/- adjuvant HER2-targeted therapy. neg, negative; pos, positive; adj, adjuvant HER 2 targeted therapy.

$\mathrm{IHCO}$ and $\mathrm{IHCl}^{+}$were considered HER2-negative, whereas $\mathrm{IHC}^{+}$was defined as HER2-positive. IHC2 ${ }^{+}$was considered borderline and in these cases HER 2 expression was further determined using the HER2 FISH pharmDx ${ }^{\mathrm{TM}}$ kit (DakoCytomation). The threshold for overexpression was a ratio equal to or exceeding 2.0 between the HER 2 gene copy number and the chromosome 17 centromere.

ER staining was carried out using an anti-human ER monoclonal antibody (clone 1D5; DakoCytomation) and visualized by the SuperSensitive polymer-HRP IHC kit (Biogenex Laboratories Inc., San Ramon, CA, USA). Tumors with a nuclei staining $\geq 10 \%$ were considered ER-positive according to the contemporary DBCG guidelines.

Statistical methods. We enrolled 400 patients to detect a $25 \%$ absolute reduction in the risk of IDFS events from 45 to $20 \%$ with $80 \%$ power and a two-sided significance level of $5 \%$. The statistical analyses were carried out using Stata version 11 software (StataCorp LP, TX, USA). Kaplan-Meier curves and the log-rank test were used to compare all time-to-event end points. Multivariate IDFS and OS analyses were performed using the Cox proportional hazards regression model. Fisher's exact test and McNemar's test were used to compare categorical data. ROC curves were used to investigate the cut-off for the quantitative Centaur assay. For all tests, two-sided P-values $<0.05$ were considered statistically significant.

\section{Results}

Patient characteristics. Final analysis included 379 patients. At the clinical cut-off date (September 19, 2011) the median follow-up was 3.9 years for IDFS and 4.2 years for OS. We compared the clinical outcome in four groups of patients defined by HER2 status (determined by IHC/FISH and Centaur) and adjuvant HER2-targeted therapy. The four groups were defined as follows: Group 0, patients defined as tissue HER2-negative by IHC/FISH and ADVIA Centaur and therefore not offered HER2-targeted therapy. Group 1, patients defined as tissue HER-positive by IHC/FISH and therefore offered HER2-targeted therapy. Group 2, patients defined as tissue HER2-positive by IHC/FISH, but not offered HER2targeted therapy, as they were older than 60 years and therefore only received endocrine treatment when adjuvant treatment was required according to the recommendations by the contemporary DBCG guidelines. Group 3, patients defined as tissue HER2-positive by ADVIA Centaur, but not by IHC/FISH and therefore not offered HER2-targeted therapy.

Table I shows patient demographics and clinical characteristics in the four groups. Clinical prognostic factors were significantly better in group 3 compared to group 1 as regards tumor grade, axillary nodal status and ER status $(\mathrm{P}=0.001,0.026$ and $<0.001$, respectively; Fisher's exact test $)$. Furthermore, Table I shows that the majority of patients in groups 1 and 2 were also defined as tissue HER2-positive by ADVIA Centaur. Likewise, differences in adjuvant treatment were observed as indicated in Table II. Significantly fewer patients in group 3 compared to group 1 received adjuvant chemotherapy $(\mathrm{P}<0.001$; Fisher's exact test).

HER2 status determined by IHC/FISH and ADVIA Centaur. Paraffin-embedded and fresh-frozen tumor tissue samples were available from all 379 patients for IHC/FISH and ADVIA Centaur analyses. The cut-off value of $72 \mathrm{ng} / \mathrm{mg}$ protein for ADVIA Centaur HER2 positivity was determined on available autologous reference tissue from 371 out of 403 patients applying a $97.5 \%$ confidence interval (CI). As shown in our previous study [Olsen et al (17)], we found the median value of HER2 to be significantly higher in the tumor tissue (median, $42.3 \mathrm{ng} / \mathrm{mg}$; range, $0-6158.2 \mathrm{ng} / \mathrm{mg}$ ) than in autologous reference tissue $(2.6 \mathrm{ng} / \mathrm{mg}$; range, $0-862.8 \mathrm{ng} / \mathrm{mg} ; \mathrm{P}<0.0001$; Wilcoxon signed rank test on 367 patients with both tumor and autologous reference tissue).

Using the cut-off value of $72 \mathrm{ng} / \mathrm{mg}$, the quantitative ADVIA Centaur defined 100 out of the 379 patients (26.4\%) as tissue HER2-positive, whereas only 63 patients $(16.6 \%)$ were defined HER2-positive by the use of IHC/FISH $(\mathrm{P}<0.0001$; 
Table I. Demographics and clinical characteristics in the four groups of patients defined by HER2 status (determined by IHC/ FISH and Centaur), +/- adjuvant HER2-targeted therapy.

\begin{tabular}{|c|c|c|c|c|c|c|c|c|c|}
\hline \multirow[b]{2}{*}{ Characteristic } & \multicolumn{2}{|c|}{$\begin{array}{c}\text { Group } 0 \\
\text { HER2-neg } \\
\text { - adj } \\
(n=274)\end{array}$} & \multicolumn{2}{|c|}{$\begin{array}{c}\text { Group } 1 \\
\text { HER2-pos } \\
\text { IHC/FISH + adj } \\
(\mathrm{n}=42)\end{array}$} & \multicolumn{2}{|c|}{$\begin{array}{c}\text { Group } 2 \\
\text { HER2-pos } \\
\text { IHC/FISH - adj } \\
(\mathrm{n}=21)\end{array}$} & \multicolumn{2}{|c|}{$\begin{array}{c}\text { Group } 3 \\
\text { HER2-pos } \\
\text { Centaur - adj } \\
(\mathrm{n}=42)\end{array}$} & \multirow[b]{2}{*}{ P-value } \\
\hline & No. & $\%$ & No. & $\%$ & No. & $\%$ & No. & $\%$ & \\
\hline \multicolumn{10}{|l|}{ Age } \\
\hline$<40$ years & 6 & 2.2 & 4 & 9.5 & & & & & \\
\hline $40-59$ years & 111 & 40.5 & 25 & 59.5 & 4 & 19.0 & 23 & 54.8 & \\
\hline$\geq 60$ years & 157 & 57.3 & 13 & 31.0 & 17 & 81.0 & 19 & 45.2 & 0.091 \\
\hline \multicolumn{10}{|l|}{ Type of surgery } \\
\hline Breast-conserving & 192 & 70.1 & 30 & 71.4 & 16 & 76.2 & 34 & 81.0 & \\
\hline Mastectomy & 82 & 29.9 & 12 & 28.6 & 5 & 23.8 & 8 & 19.0 & 0.443 \\
\hline \multicolumn{10}{|l|}{ Tumor type } \\
\hline Ductal & 236 & 86.1 & 38 & 90.5 & 19 & 90.5 & 37 & 88.1 & \\
\hline Lobular & 21 & 7.7 & 2 & 4.8 & & & 2 & 4.8 & \\
\hline Others & 17 & 6.2 & 2 & 4.8 & 2 & 9.5 & 3 & 7.1 & 1.000 \\
\hline \multicolumn{10}{|l|}{ Tumor grade } \\
\hline Grade 1 & 68 & 24.8 & 1 & 2.4 & 1 & 4.8 & 12 & 28.6 & \\
\hline Grade 2 & 132 & 48.2 & 20 & 47.6 & 7 & 33.3 & 21 & 50.0 & \\
\hline Grade 3 & 56 & 20.4 & 17 & 40.5 & 11 & 52.4 & 6 & 14.3 & \\
\hline Unknown & 18 & 6.6 & 4 & 9.5 & 2 & 9.5 & 3 & 7.1 & 0.001 \\
\hline \multicolumn{10}{|l|}{ Tumor size } \\
\hline $\mathrm{T} 1 \leq 20 \mathrm{~mm}$ & 130 & 47.4 & 17 & 40.5 & 9 & 42.9 & 24 & 57.1 & \\
\hline $\mathrm{T} 2>0 \leq 50 \mathrm{~mm}$ & 138 & 50.4 & 24 & 57.1 & 12 & 57.1 & 18 & 42.9 & \\
\hline $\mathrm{T} 3>50 \mathrm{~mm}$ & 6 & 2.2 & 1 & 2.4 & & & & & 0.190 \\
\hline \multicolumn{10}{|l|}{ Nodal status } \\
\hline N0, 0 nodes & 127 & 46.4 & 18 & 42.9 & 11 & 52.4 & 26 & 61.9 & \\
\hline N1, 1-3 nodes & 106 & 38.7 & 12 & 28.6 & 8 & 38.1 & 14 & 33.3 & \\
\hline N2, 4-9 nodes & 28 & 10.2 & 8 & 19.0 & 2 & 9.5 & 1 & 2.4 & \\
\hline $\mathrm{N} 3, \geq 10$ nodes & 13 & 4.7 & 4 & 9.5 & & & 1 & 2.4 & 0.026 \\
\hline \multicolumn{10}{|l|}{ ER status } \\
\hline Negative & 38 & 13.9 & 18 & 42.9 & 6 & 28.6 & 3 & 7.1 & \\
\hline Positive & 236 & 86.1 & 24 & 57.1 & 15 & 71.4 & 39 & 92.9 & $<0.001$ \\
\hline \multicolumn{10}{|l|}{ HER2 IHC/FISH } \\
\hline Negative & 274 & & & & & & 42 & & \\
\hline Positive & & & 42 & & 21 & & & & NA \\
\hline \multicolumn{10}{|l|}{ HER2 Centaur } \\
\hline Negative $<72 \mathrm{ng} / \mathrm{mg}$ & 274 & & 4 & & 1 & & & & \\
\hline Positive $\geq 72 \mathrm{ng} / \mathrm{mg}$ & & & 38 & & 20 & & 42 & & NA \\
\hline
\end{tabular}

McNemar's test). The ADVIA centaur misclassified only 5 out of the 63 patients defined as tissue HER2-positive by IHC/ FISH as shown in Table I. Fig. 2 shows the distribution of
ADVIA Centaur values according to the four different groups; it should be noted that only five values in groups 1 and 2 are below the cut-off value of $72 \mathrm{ng} / \mathrm{mg}$. 
Table II. Adjuvant therapy in the four groups of patients defined by HER2 status (determined by IHC/FISH and Centaur), +/- adjuvant HER2-targeted therapy.

\begin{tabular}{|c|c|c|c|c|c|c|c|c|c|}
\hline \multirow{2}{*}{$\begin{array}{l}\text { Adjuvant } \\
\text { therapy }\end{array}$} & \multicolumn{2}{|c|}{$\begin{array}{c}\text { Group } 0 \\
\text { HER2-neg } \\
\text { - adj } \\
(n=274)\end{array}$} & \multicolumn{2}{|c|}{$\begin{array}{c}\text { Group } 1 \\
\text { HER2-pos } \\
\text { IHC/FISH + adj } \\
\quad(n=42)\end{array}$} & \multicolumn{2}{|c|}{$\begin{array}{c}\text { Group } 2 \\
\text { HER2-pos } \\
\text { IHC/FISH - adj } \\
(n=21)\end{array}$} & \multicolumn{2}{|c|}{$\begin{array}{c}\text { Group } 3 \\
\text { HER2-pos } \\
\text { Centaur - adj } \\
\quad(n=42)\end{array}$} & \multirow[b]{2}{*}{ P-value ${ }^{a}$} \\
\hline & No. & $\%$ & No. & $\%$ & No. & $\%$ & No. & $\%$ & \\
\hline \multicolumn{10}{|c|}{ Chemotherapy } \\
\hline No & 171 & 62.4 & 1 & 2.4 & 19 & 90.5 & 23 & 54.8 & \\
\hline $\mathrm{CEF}$ & 42 & 15.3 & 13 & 31.0 & & & 4 & 9.5 & \\
\hline $\mathrm{CMF}$ & 1 & 0.4 & 1 & 2.4 & 2 & 9.5 & & & \\
\hline $\mathrm{EC}+\mathrm{D}$ & 47 & 17.2 & 27 & 64.3 & & & 14 & 33.3 & \\
\hline $\mathrm{DC}$ & 13 & 4.7 & & & & & 1 & 2.4 & $<0.001$ \\
\hline \multicolumn{10}{|c|}{ HER2-targeted } \\
\hline No & 274 & 100.0 & & & 21 & 100.0 & 42 & 100.0 & \\
\hline Herceptin & & & 28 & 66.7 & & & & & \\
\hline Neratinib $^{\mathrm{b}}$ & & & 4 & 9.5 & & & & & \\
\hline Lapatinib $^{\text {b }}$ & & & 10 & 23.8 & & & & & $<0.001$ \\
\hline \multicolumn{10}{|l|}{ Endocrine } \\
\hline No & 70 & 25.5 & 17 & 40.5 & 7 & 33.3 & 11 & 26.2 & \\
\hline Tam & 45 & 16.4 & 7 & 16.7 & 1 & 4.8 & 6 & 14.3 & \\
\hline $\mathrm{Tam}+\mathrm{AI}^{\mathrm{c}}$ & 107 & 39.1 & 7 & 16.7 & 7 & 33.3 & 16 & 38.1 & \\
\hline AI & 52 & 19.0 & 11 & 26.2 & 6 & 28.6 & 9 & 21.4 & 0.165 \\
\hline \multicolumn{10}{|l|}{ Radiotherapy } \\
\hline No & 49 & 17.9 & 4 & 9.5 & 6 & 28.6 & 6 & 14.3 & \\
\hline Yes & 225 & 82.1 & 38 & 90.5 & 15 & 71.4 & 36 & 85.7 & 0.738 \\
\hline
\end{tabular}

${ }^{a}$ Differences in the adjuvant therapy in groups 1 and 3 were compared by Fisher's exact test. ${ }^{\mathrm{b}}$ In combination with Herceptin. ${ }^{\mathrm{c}}$ Tamoxifen followed by an aromatase inhibitor. neg, negative; pos, positive; adj, adjuvant HER2 targeted therapy.

Table III. Univariate analysis of prognostic factors for IDFS and OS in the 379 patients.

\begin{tabular}{lrr}
\hline Factor & $\begin{array}{c}\text { IDFS } \\
\text { P-value }\end{array}$ & $\begin{array}{c}\text { OS } \\
\text { P-value }\end{array}$ \\
\hline Group & 0.159 & 0.150 \\
Age, $<60$ vs. $\geq 60$ years & 0.207 & 0.055 \\
Tumor grade, grade $<3$ vs. grade 3 & $<0.001$ & $<0.001$ \\
Tumor size, $\leq 20$ vs. $>20 \mathrm{~mm}$ & 0.058 & 0.009 \\
Lymph nodes, neg/pos & 0.206 & 0.012 \\
ER status, neg/pos & 0.111 & 0.049 \\
HER2 IHC/FISH, neg/pos & 0.228 & 0.522 \\
HER2 Centaur, $<72$ vs. $\geq 72 \mathrm{ng} / \mathrm{mg}$ & 0.651 & 0.670 \\
\hline
\end{tabular}

Univariate analysis was performed using the log-rank test. Median follow-up was 3.9 years for IDFS and 4.2 years for OS. neg, negative; pos, positive.

Invasive disease-free survival. Follow-up was available for all 379 patients in the final analysis. At a median follow-up of
3.9 years (0.3-6.9 years), there were 74 events in the four groups, 45 distant recurrence, 11 regional invasive breast cancer recurrence or ipsilateral/contralateral invasive breast cancer, 10 died from non-breast cancer/unknown cause, and eight had second primary non-breast invasive cancer. No significant difference in IDFS was found among the four groups ( $\mathrm{P}=0.159$; log-rank). Surprisingly, we found a significantly greater number of events in group 2 compared to group 3 ( $\mathrm{P}=0.025$; log-rank), with eight events in 21 patients in the IHC/FISH-positive group not receiving adjuvant HER2-targeted treatment (group 2) and only five events in 42 patients in the Centaur-positive group not receiving adjuvant HER2-targeted treatment (group 3) (Fig. 3).

Overall survival. At a median follow-up of 4.2 years (0.3-6.9 years), the four groups had a total of 39 events (29 died from breast cancer and 10 died from non-breast cancer/unknown cause). As for IDFS, no significant difference in survival was observed among the four groups ( $\mathrm{P}=0.150$; log-rank); however, a significantly higher number of deaths was observed in group 2 compared to group 3 ( $\mathrm{P}=0.020$; log-rank) (Fig. 4).

Univariate and multivariate analysis. Table III shows the results of the univariate analysis with dichotomized variables, 


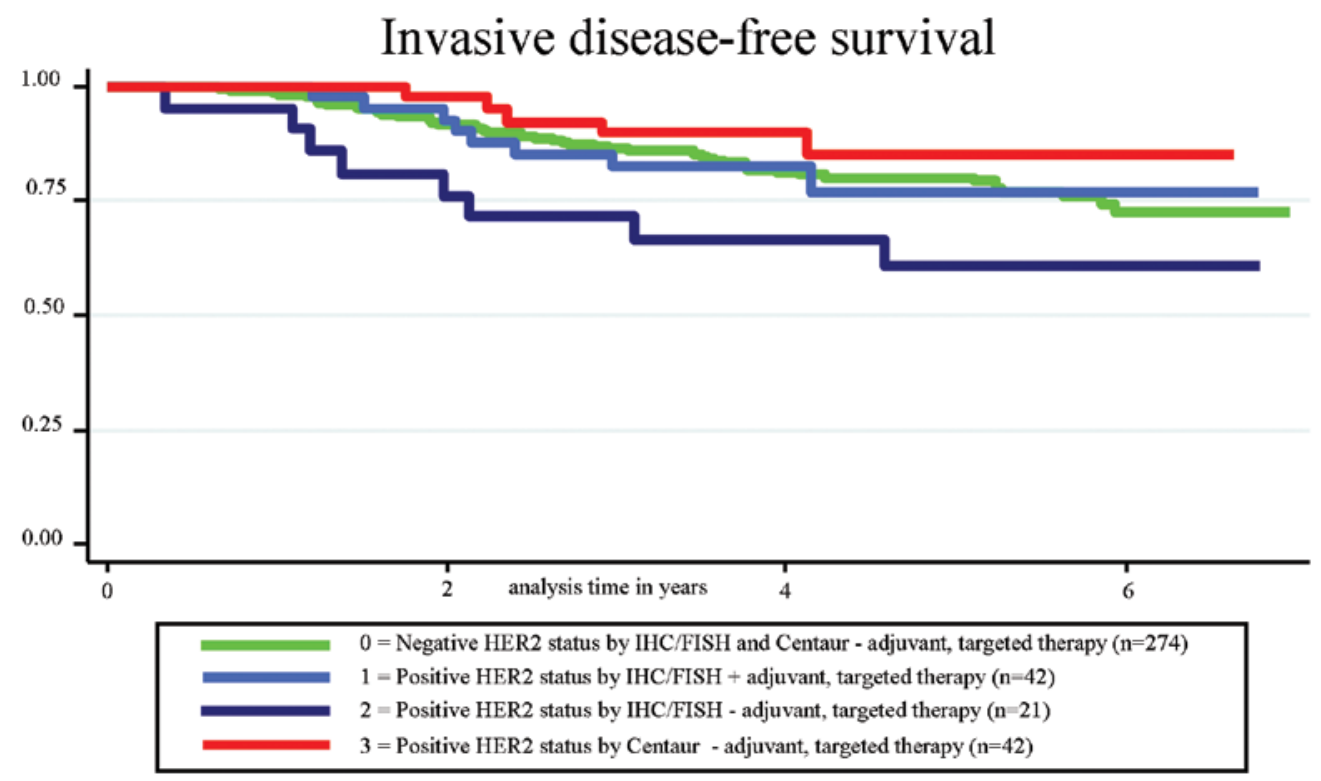

Figure 3. Kaplan-Meier plot showing invasive disease-free survival in the four groups of patients based on HER2 status (determined by IHC/FISH and Centaur), +/- adjuvant HER2-targeted therapy.

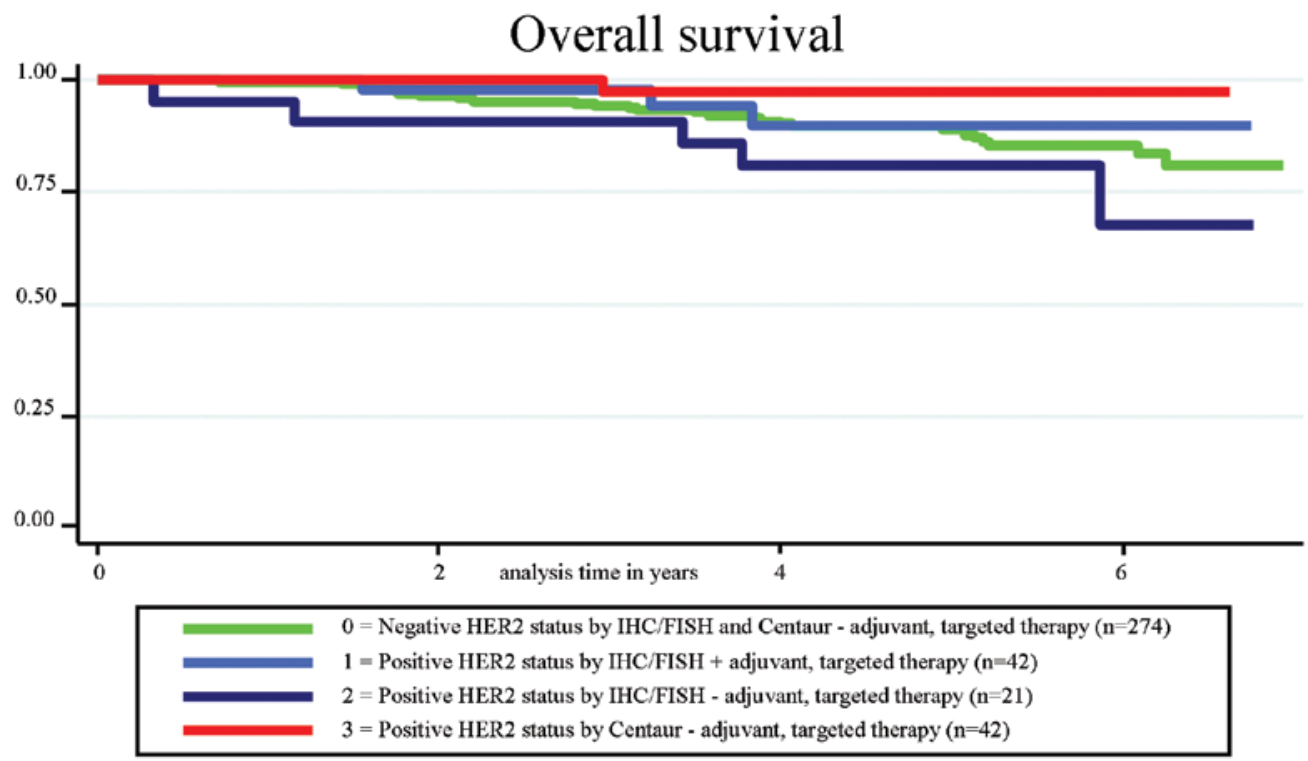

Figure 4. Kaplan-Meier plot showing overall survival in the four groups of patients based on HER2 status (determined by IHC/FISH and Centaur), +/- adjuvant HER 2-targeted therapy.

identifying tumor grade (grade of $<3$ vs. grade 3), tumor size ( $\leq 20 \mathrm{vs.}>20 \mathrm{~mm}$ ), axillary node status (negative vs. positive) and estrogen receptor status (negative vs. positive) as statistically significant for OS, whereas only tumor grade was statistically significant for IDFS. HER2 status (negative vs. positive) was not significant in the univariate analysis, neither when determined by IHC/FISH nor by Centaur ( $<72 \mathrm{vs.} \geq 72 \mathrm{ng} / \mathrm{mg}$ ).

The variables in the multivariate analysis included group (also representing HER2 status), age, tumor grade, tumor size, axillary node status and ER-status as outlined in Table IV. In the multivariate analysis for IDFS, the only independent prognostic marker was tumor grade $(\mathrm{P}=0.011)$. In the multivariate analysis for OS age $(\mathrm{P}=0.048)$, tumor grade $(\mathrm{P}=0.010)$ and axillary node status $(\mathrm{P}=0.025)$ were independent prognostic markers. Groups determined by HER2 status were not an independent prognostic factor in the above analysis.

ROC curve analysis. We also investigated the ability of the quantitative Centaur assay to discriminate between patients with or without recurrence. The ROC curve analyses resulted in an almost straight line with an area under the ROC curve of 0.49 , which implies that the Centaur assay was not able to discriminate between patients at all. In accordance with this finding, there were no statistically significant differences observed between the mean Centaur value in patients with or without recurrence in any of the four groups of patients in this study (data not shown). 
Table IV. Multivariate analysis of prognostic factors for IDFS and OS in 379 patients.

\begin{tabular}{|c|c|c|c|c|}
\hline \multirow[b]{2}{*}{ Factor } & \multicolumn{2}{|c|}{ IDFS } & \multicolumn{2}{|c|}{ OS } \\
\hline & HR $(95 \% \mathrm{CI})$ & P-value & HR $(95 \% \mathrm{CI})$ & P-value \\
\hline \multicolumn{5}{|l|}{ Group } \\
\hline 0, HER2-neg - adj & 1.00 & & 1.00 & \\
\hline 1, IHC/FISH pos + adj. & $0.94(0.43-2.05)$ & 0.879 & $0.72(0.21-2.49)$ & 0.602 \\
\hline 2, IHC/FISH pos - adj. & $1.49(0.69-3.21)$ & 0.306 & $1.29(0.49-3.39)$ & 0.602 \\
\hline 3, Centaur pos - adj. & $0.65(0.26-1.62)$ & 0.352 & $0.27(0.04-2.01)$ & 0.202 \\
\hline \multicolumn{5}{|l|}{ Age } \\
\hline$<60$ years & 1.00 & & 1.00 & \\
\hline$\geq 60$ years & $1.35(0.83-2.22)$ & 0.231 & $2.04(1.00-4.15)$ & 0.048 \\
\hline \multicolumn{5}{|l|}{ Tumor grade } \\
\hline Grade 1,2 , unknown & 1.00 & & 1.00 & \\
\hline Grade 3 & $1.94(1.16-3.24)$ & 0.011 & $2.48(1.24-4.97)$ & 0.010 \\
\hline \multicolumn{5}{|l|}{ Tumor size } \\
\hline$\leq 20 \mathrm{~mm}$ & 1.00 & & 1.00 & \\
\hline$>20 \mathrm{~mm}$ & $1.32(0.80-2.17)$ & 0.624 & $1.80(0.85-3.83)$ & 0.124 \\
\hline \multicolumn{5}{|l|}{ Axillary node status } \\
\hline Negative & 1.00 & & 1.00 & \\
\hline Positive & $1.33(0.82-2.17)$ & 0.245 & $2.32(1.11-4.83)$ & 0.025 \\
\hline \multicolumn{5}{|l|}{ ER status } \\
\hline Negative & 1.00 & & 1.00 & \\
\hline Positive & $0.78(0.43-1.41)$ & 0.411 & $0.60(0.28-1.29)$ & 0.195 \\
\hline
\end{tabular}

Statistical analysis was performed by the Cox regression analysis. Median follow-up was 3.9 years for IDFS and 4.2 years for OS. neg, negative; pos, positive; adj, adjuvant HER2 targeted therapy.

\section{Discussion}

In the current study, we reject the hypothesis that the clinical outcome is worse in a group of patients defined as tissue HER2-positive by Centaur only and not treated with adjuvant HER2-targeted therapy compared to patients defined as HER2positive by IHC/FISH and treated with adjuvant HER2-targeted therapy. In fact, the best outcome was observed in the group of patients defined as HER2-positive by Centaur only. In contrast to this finding, Konecny et al (18) demonstrated an association between HER2 overexpression by ELISA and shorter diseasefree survival (DFS) in a cohort of 587 patients with primary breast cancer prior to the era of HER2-targeted therapy. Currently, adjuvant HER2-targeted therapy is the standard of care for HER2-positive breast cancer patients. Scrutiny of the clinically relevant question as to whether we could increase the number of patients eligible for adjuvant HER2-targeted therapy could only be done in a design such as the present one followed by a prospective intervention study.

A number of studies have indicated the existence of an additional group that may benefit from adjuvant HER2-targeted therapy. First, as shown in a previous study [HERceptin Adjuvant (HERA) trial], among patients defined as HER2positive by IHC and FISH (IHC2 ${ }^{+}$and $\mathrm{FISH}^{+}$), a significant improvement in clinical outcome was observed in patients treated with adjuvant chemotherapy plus trastuzumab for one year (19). Second, Gilcrease et al (20) demonstrated that even a low-level HER 2 expression $\left(\mathrm{IHCl}^{+}\right)$can be associated with a worse outcome in node-positive patients. Finally, the study by Viale raised an ongoing discussion regarding the misclassification of some patients by FISH using HER2/CEP17 ratio instead of relating the HER 2 copy number to the cell count (21).

The cut-off value of $72 \mathrm{ng} / \mathrm{mg}$ used in this study is consistent with the cut-off value of $400 \mathrm{fmol} / \mathrm{mg}(\sim 74 \mathrm{ng} / \mathrm{mg})$ found by Konecny et al (18), who optimized the cut-off value to provide the maximum separation of patients according to DFS. On the other hand, Müller et al (22) applied ROC statistics to optimize their cut-off value ( $42 \mathrm{ng} / \mathrm{mg}$ ) according to the FISH results. If we had used this lower cut-off value, we would have defined $51 \%$ of the patients as HER2-positive (193 out of 379 patients). In contrast to these two studies, we aimed to find a novel and more sensitive assay and therefore chose to investigate Centaur HER2 as a biological variable and defined the cut-off value in our study according to the autologous reference tissue by applying a $97.5 \% \mathrm{CI}$.

Another unexpected, although interesting finding of this study was that the HER2-positive patients in group 2 (age $\geq 60$ ) had a worse outcome than expected, possibly due to the lack of adjuvant HER2-targeted therapy. This emphasizes the need for a change in clinical practice where many elderly patients 
are not selected for adjuvant chemotherapy and HER2-targeted therapy based on age only. Furthermore, Palmieri et al (23) reported a worse outcome in patients who were not offered HER2-targeted therapy due to a clinical judgment that the breast cancer was low-risk. Likewise, Tovey et al (24) emphasized the need for HER2-targeted therapy even in low-grade, node-negative tumors. Sawaki et al (25) showed that elderly patients tolerated trastuzumab well, which highlights the need for a new view of elderly patients and adjuvant HER2-targeted therapy.

In conclusion, the main finding of the present study is that quantitative the detection of HER 2 concentration using Centaur does not define a new group of patients eligible for HER2-targeted therapy. Therefore, tissue HER2 status defined by IHC/FISH analysis remains the gold standard. HER2 amplification is presumably the decisive factor, which, in addition to an overexpression of the HER2 protein, leads to the aggressive nature of HER2-positive tumors. Further studies are therefore warranted in order to identify novel methods of detecting this amplification.

\section{Acknowledgements}

The study was financed by the Vejle Hospital Research Foundation. HER 2 kits were kindly granted by Siemens Healthcare Diagnostics (Deerfield, IL, USA). The authors thank Sara Egsgaard and Camilla Davidsen for their laboratory work, and Karin Larsen for proofreading.

\section{Conflicts of interest}

I.B. and T.B. have received remuneration for two lectures on serum HER2 from Siemens Healthcare Diagnostics.

\section{References}

1. Kurebayashi J: Biological and clinical significance of HER2 overexpression in breast cancer. Breast Cancer 8: 45-51, 2001.

2. Carney WP, Neumann R, Lipton A, et al: Potential clinical utility of serum HER-2/neu oncoprotein concentrations in patients with breast cancer. Clin Chem 49: 1579-1598, 2003.

3. Pauletti G, Dandekar S, Rong H, et al: Assessment of methods for tissue-based detection of the HER-2/neu alteration in human breast cancer: a direct comparison of fluorescence in situ hybridization and immunohistochemistry. J Clin Oncol 18: 3651-3664, 2000.

4. Slamon DJ: Human breast cancer: correlation of relapse and survival with amplification of the HER-2/neu oncogene. Science 235: 177-182, 1987.

5. Slamon DJ, Leyland-Jones B, Shak S, et al: Use of chemotherapy plus a monoclonal antibody against HER2 for metastatic breast cancer that overexpresses HER2. N Engl J Med 344: 783-792, 2001.

6. Piccart-Gebhart MJ, Procter M, Leyland-Jones B, et al: Trastuzumab after adjuvant chemotherapy in HER2-positive breast cancer. N Engl J Med 353: 1659-1672, 2005.
7. Romond EH, Perez EA, Bryant J, et al: Trastuzumab plus adjuvant chemotherapy for operable HER2-positive breast cancer. N Engl J Med 353: 1673-1684, 2005.

8. Gong Y, Booser DJ and Sneige N: Comparison of HER-2 status determined by fluorescence in situ hybridization in primary and metastatic breast carcinoma. Cancer 103: 1763-1769, 2005.

9. Zidan J, Dashkovsky I, Stayerman C, et al: Comparison of HER-2 overexpression in primary breast cancer and metastatic sites and its effect on biological targeting therapy of metastatic disease. $\mathrm{Br}$ J Cancer 93: 552-556, 2005.

10. Gancberg D, Di LA, Cardoso F, et al: Comparison of HER-2 status between primary breast cancer and corresponding distant metastatic sites. Ann Oncol 13: 1036-1043, 2002.

11. Wolff AC, Hammond ME, Schwartz JN, et al: American Society of Clinical Oncology/College of American Pathologists guideline recommendations for human epidermal growth factor receptor 2 testing in breast cancer. J Clin Oncol 25: 118-145, 2007.

12. Tse C, Brault D, Gligorov J, et al: Evaluation of the quantitative analytical methods real-time PCR for HER-2 gene quantification and ELISA of serum HER-2 protein and comparison with fluorescence in situ hybridization and immunohistochemistry for determining HER-2 status in breast cancer patients. Clin Chem 51: 1093-1101, 2005.

13. Bergqvist J, Ohd JF, Smeds J, et al: Quantitative real-time PCR analysis and microarray-based RNA expression of HER 2 in relation to outcome. Ann Oncol 18: 845-850, 2007.

14. Egervari K, Toth J, Nemes Z and Szollosi Z: An alternative and reliable real-time quantitative PCR method to determine HER2/neu amplification in breast cancer. Appl Immunohistochem Mol Morphol 17: 247-254, 2009.

15. Olsen DA, Ostergaard B, Bokmand S, et al: HER-2 protein concentrations in breast cancer cells increase before immunohistochemical and fluorescence in situ hybridization analysis turn positive. Clin Chem Lab Med 45: 177-182, 2007.

16. Hudis CA, Barlow WE, Costantino JP, et al: Proposal for standardized definitions for efficacy end points in adjuvant breast cancer trials: the STEEP system. J Clin Oncol 25: 2127-2132, 2007.

17. Olsen DA, Bechmann T, Ostergaard B, et al: Increased concentrations of growth factors and activation of the EGFR system in breast cancer. Clin Chem Lab Med 50: 1809-1818, 2012.

18. Konecny G, Untch M, Arboleda J, et al: Her-2/neu and urokinasetype plasminogen activator and its inhibitor in breast cancer. Clin Cancer Res 7: 2448-2457, 2001.

19. Dowsett M, Procter M, Caskill-Stevens W, et al: Disease-free survival according to degree of HER2 amplification for patients treated with adjuvant chemotherapy with or without 1 year of trastuzumab: the HERA Trial. J Clin Oncol 27: 2962-2969, 2009.

20. Gilcrease MZ, Woodward WA, Nicolas MM, et al: Even low-level HER2 expression may be associated with worse outcome in node-positive breast cancer. Am J Surg Pathol 33: 759-767, 2009.

21. Viale G: Be precise! The need to consider the mechanisms for CEP17 copy number changes in breast cancer. J Pathol 219: 1-2, 2009.

22. Müller V, Thomssen C, Karakas C, et al: Quantitative assessment of HER-2/neu protein concentration in breast cancer by enzymelinked immunosorbent assay. Int J Biol Markers 18: 13-20, 2003.

23. Palmieri C, Shah D, Krell J, et al: Management and outcome of HER2-positive early breast cancer treated with or without trastuzumab in the adjuvant trastuzumab era. Clin Breast Cancer 11: 93-102, 2011.

24. Tovey SM, Brown S, Doughty JC, et al: Poor survival outcomes in HER2-positive breast cancer patients with low-grade, nodenegative tumours. Br J Cancer 100: 680-683, 2009.

25. Sawaki M, Mukai H, Tokudome N, et al: Safety of adjuvant trastuzumab for HER-2-overexpressing elderly breast cancer patients: a multicenter cohort study. Breast Cancer 19: 253-258, 2012. 